\title{
Prenatal Methamphetamine Exposure could Cause Chronic Abnormalities in Transcriptomic Pattern; an Extended Follow-up Cohort Study
}

\section{Arvin Haghighatfard ( $\sim$ arvinland@yahoo.com )}

department of genetics, Tehran Medical sciences, Islamic Azad University, Tehran, Iran

https://orcid.org/0000-0002-2179-9822

\section{Soha Seifollahi}

Department of Genetics, Tehran Medical sciences, islamic Azad University, Tehran, Iran

\section{Pegah Rajabi}

Islamic Azad University of Tehran: Islamic Azad University Central Tehran Branch

\section{Niloofar Rahmani}

department of genetics, Tehran medical sciences, Islamic Azad university, Tehran, Iran

\section{Rojin Ghannad zadeh}

department of genetics, Tehran medical sciences branch, Islamic Azad university, Tehran, Iran

\section{Research article}

Keywords: prenatal methamphetamine exposure, gene expression, microarray, follow up

Posted Date: January 15th, 2021

DOI: https://doi.org/10.21203/rs.3.rs-144191/v1

License: (c) (i) This work is licensed under a Creative Commons Attribution 4.0 International License. Read Full License 


\section{Abstract}

\section{Background}

The high rate of methamphetamine abuse among young adults and women of childbearing age makes it imperative to clarify the long-term effects of Methamphetamine exposure on the offspring. Behavioral and cognitive problems had reported in children with parental Methamphetamine exposure (PME). The present study aimed to assess the acute and chronic effects of PME in molecular regulations and gene expression profiles of children during their first years of life.

\section{Results}

All subjects were recruited before birth, and sampling was conducted from the first ten days of birth, twelve months, twenty months and thirty-six months of age. Finally, 2658 children with PME and 3573 normal children had been finished the follow-up. RNA extraction was operated from blood samples and gene expression profiling was conducted by using the Affymetrix GeneChip Human Genome U133 plus 2.0 Array Platform. Gene expression data were confirmed by Real-time PCR. Gene expression profiling during thirty-six months showed several constant mRNA level alterations in children with PME compared with normal. These genes are involved in several gene ontology and pathways involved with the immune system, neuronal functions and bioenergetic metabolism. It seems that Methamphetamine abuse before and during the pregnancy period may affect the expression profile of children, and these changes could be remain years after birth. Affected genes have some similarities to the gene expression patterns of addiction, psychiatric disorders, neurodevelopmental disabilities and immune deficiencies.

\section{Conclusion}

Findings may shed light on the molecular effects of prenatal methamphetamine exposure and may lead to new psychological and somatic caring protocols for these children based on their potential abnormalities.

\section{Background}

Methamphetamine is a psychostimulant, neurotoxic drug that causes chronically psychological dependence in the abuser. Methamphetamine (MA) abuse is a global problem, and its abusers are more than cocaine and opiates combined (1). Gender analysis showed that female first-time users of methamphetamine are more than male first-time users (2). On the other hand, only less than fifty percent of those women are seeking treatment. In the United States, about seven percents of MA dependents that were referred to clinics for treatment were pregnant women (3).

Previous studies about the effects of prenatal methamphetamine exposure on child development showed an increase in gestational size at birth and decreased length through three years. Deficiency in movement and arousal along with increased stress signs in the newborn period and poor grasping ability at one to 
three years old children were reported(4). Further studies in the age of three to five years have been shed light on attentional issues such as inhibitory control, aggressive behavior, and adjustment issues that could be related to abnormalities in the development of executive function in prenatal methamphetamine exposure children $(5,6)$.

Acute and chronic methamphetamine abusers show severs behavioral problems, including addictive behaviors such as craving, salience, and psychotic symptoms such as aggressiveness, hallucination, and dilution. Also, individuals with methamphetamine dependence have a higher risk of schizophrenia (7). While it is approved that methamphetamine is a highly addictive substance with widespread and constant effects in the central nervous system (CNS), its molecular mechanisms on adult and fetus are not clarified. Methamphetamine increased blood-brain barrier (BBB) permeability by rearrangement of $\mathrm{F}$ actin cytoskeleton and reduction of tight junction (TJ) proteins (8). Mouse model assessments were reported that increased total DNA methylation in the mPFC could be associated with mPFC malfunction and long-term cognitive decline (9).

While there is a lack of information about molecular mechanisms of methamphetamine and its effects on the development of CNS, neuroimaging studies provide valuable evidence about the role of prenatal methamphetamine exposure in functional and structural changes in the brain (10). Methamphetamine abuse in adult persons could decrease the metabolism in the insula and frontal cortex and an increase in basal ganglia (11). However, diffusion tensor imaging (DTI) studies have reported that prenatal exposure to methamphetamine is more associated with white matter microstructure alterations (12). Alteration such as diffusion measures in white matter connections and reduction of fractional anisotropy (FA) in several connections between the striatum and midbrain $(12,13)$.

Based on some studies, mood difficulties, cognitive deficiencies, and chronic behavioral abnormalities are increased in PME children in childhood and maybe adolescence (14). Early detection of vulnerable children and psychological caring may prevent severe social and psychiatric problems in the next generation. That is why a general pattern of all alterations caused by prenatal methamphetamine exposure in molecular, neuroanatomical, and behavioral levels is highly needed (14).

The present study aimed to comprehensively evaluate the acute (or early) and chronically (or longstanding) effects of prenatal methamphetamine exposure in gene expression profile, behavior, and neuronal activities in the brain. We followed up a large sample size of children with prenatal methamphetamine exposure from date of birth to thirty-six months of age by using a functional genomewide profiling approach.

\section{Results}

Demographic and clinical data of subjects are available in table 2.

\section{DNA microarray results}


Initial filtering with MAS 5.0 based on significance, fold change, and the effect size was showed 1234 genes differently expressed (626 up-regulated genes, 608 down-regulated genes) in PME infants vs. normal infants. In twelve months sampling 1103 genes (572 up-regulated genes,531 down-regulated genes), in twenty-four months sampling 976 genes (561 up-regulated genes, 415 down-regulated genes), and in thirty-six months sampling 1006 genes (628 up-regulated genes,378 down-regulated genes) were differently expressed in PME children vs. normal children. Final results were calculated after FDR correction $(p<0.01)$, the ANOVA, and post hoc analysis $(p<0.01)$ along with Bonferroni multiplecomparison correction. Details list of differentially expressed genes in microarray in all comparisons between PME groups and normal subjects have been presented at supplementary data. Total gene expression differentiation in each sampling during the follow up are shown in figure 1.

\section{DAVID and KEGG analysis}

In order to reveal the molecular and cellular functional characteristics and pathways affected by PME, all of the DEGs were subjected to enriched gene ontology calculations, pathway analysis by KEGG pathways and DAVID, and findings were presented in table 3 , table 4 and figure 2 respectively.

\section{Potential biomarker prediction analysis}

QPCR confirmation was conducted on 17 DEGs to validate changes in gene expression from the microarray analysis. Genes were selected based on fold changes, p-value, intensity threshold and KNN classification algorithm. Real-time PCR confirmations in these significantly altered genes were showed the same alterations in the same directions with those observed in the microarray. All genes in this list were showed the same direction in expression in all follow-up samplings. The comparison of the fold change obtained from qPCR and microarray determined a significant correlation between techniques $(P<$ $0.0001, r=0.874)$ that shows confirmations by $\mathrm{qPCR}$ indicated a strong reproducibility of genes expression results. Results of biomarker assessments showed a shortlist of candidate genes with high sustainity during the follow-up, which was determined in table 5 and figure 3 . Primers of analyzed genes in QPCR presented in table 6.

\section{Discussion}

Substance abuse during pregnancy is a pandemic proportion worldwide. Primarily the effects of prenatal cigarette use on the fetus were first identified in the 60's decade, and then effects of alcohol, opiate, and the effects of several illicit drugs have been revealed. Recently studies have focused on the effects of prenatal exposure to CNS stimulant drugs $(14,17)$. Although there are several reports about the molecular, cognitive and brain structure of methamphetamine abuse, there is a great lack of information about PMEs. Few animal model reports studied the PME effects on molecular pathways in the brain $(18,19,20)$. In addition, some psychological studies evaluated the cognitive effects of PME in children at the age of six or seven or adolescence $(21,22)$. To our knowledge, the present study is the first gene 
expression analysis of PME children and also is the first follow-up study of PMEs for a long term of a period and in a cohort big sample size. Especially the long term follow-up may help to separate the acute and temporary alterations of meth toxicity such as hepatotoxicity from chronic and constant changes such as neurodevelopment or immunodeficiency.

\section{Gene ontology assessments}

Genome expression profiling on methamphetamine treated animal model studies showed changes in critical genes for brain functions, including neuronal plasticity, mitochondrial energy metabolism and immune response (23). METH treatment induction on mitochondrial energy metabolism and associated

glutamate receptor alterations as a neurotoxic response in the brain (including the amygdala, prefrontal cortex, hippocampus and striatum) of rats accompanied with a significant behavioral sensitization had reported $(24,25)$. The present study may suggest that PME may induce chronic bioenergetic deregulations in children that, in turn, could increase the possibility of severe psychiatric disorders caused by mitochondrial dysfunction. Mitochondrial energy metabolism provides energy for brain functions and mitochondrial dysfunction are biomarkers for severe psychiatric disorders such as schizophrenia, bipolar disorder, and major depression disorders $(26,27)$ especially complex I of the respiratory chain that is highly affected by PME are known to be associated with psychosis and number of cognitive dysfunctions in schizophrenia (28). Neuron projection, which is the most affected cellular component during the follow up is any process extending from a neural cell, such as axons or dendrites and is related to addiction tendency and stress problems and changes in brain circuitry $(29,30)$. Synaptic transmission and transmission of nerve impulse are two biological processes that are affected in all samplings during the 36 months in PMEs. Synaptic transmission is essential for normal cognitive functions such as learning and memory (31). Dysfunction in synaptic transmission and transmission of nerve impulses had reported in a number of psychiatric disorders such as schizophrenia and autism(32,33). Findings may explain the learning and cognitive problem $(34,35)$ and even anatomical changes in the brain of PMEs, such as reduced caudate and thalamus volume (36).

\section{Pathway analysis}

Probably the major and sever Primary immunodeficiency is the most worrying effect of PME observed in present study. METH treatment may cause an inflammatory response that plays a potential role in METHinduced neuronal injury and $d$ regulation of cellular immune responses $(37,38,39)$. METH also could increase blood-brain barrier (BBB) permeability that may explain similarities between PMEs and methamphetamine abusers(8), but taking together with primary immunodeficiency could increase the risk of several CNS infections in PMEs. There is comprehensive literature about methamphetamine role in immune deficiency and pathogenesis of Human immunodeficiency virus (HIV) $(40,41)$. Immunodeficiency caused by methamphetamine can get escalated when accompanied by mitochondrial damage and increased levels of oxidative stress (42). By the way, primary immunodeficiency diseases (PIDs) are a 
group of more than 300 different heterogeneous disorders, and many PIDs patients are diagnosed late. Due to poor prognosis, many cases suffer from complications by the burden of chronic infections, irretrievable end-organ damage, or even death before the definitive diagnosis $(43,44)$. Results revealed that PMEs are born at risk of lethal immunodeficiency disorders. But the bright side is that the targeted prognosis of PMEs may lead to timely diagnosis and appropriate treatment of those PMEs who may affect by PIDs. Recent epidemiological cohort studies showed that methamphetamine abuse increases the risk for developing Parkinson's disease (PD) and there are similar neurodegenerative processes in PDs and Meth abusers that target the nigrostriatal system $(45,46$.). In addition, Parkinson's disease pathway is mostly involved with dopaminergic and GABAergic pathways(47). Addiction tendency, number of psychiatric disorders including schizophrenia and attention deficit hyperactivity disorder (ADHD) and behavioral abnormalities such as anxiety and low-stress resilience are associated with overexpression of dopamine and GABA receptors, dopamine synthesis genes and downexpression of genes involved in the degradation of dopamine (48). Constant and severe deregulation of Parkinson related genes in PMEs provide evidence that prenatal methamphetamine exposure can cause long-lasting disabilities or degeneration of dopaminergic cell bodies, and it may increase the risk of PD in PMEs as well as Meth abusers. Also, these potential risks for PD can be detected in neonates.

The number of deregulations caused by methamphetamine, including reactive oxygen species activation and mitochondrial dysfunctions may lead to death receptor and ER pathways of apoptosis $(49,50)$. Methamphetamine-induced apoptosis pathways are mostly mitochondria-mediated (51), but also the footprint of the mTOR signaling pathway were detected $(52,53)$. Several genes from both mitochondrial and mTOR were differentially expressed in PMEs. mTOR pathway is also associated with autistic-like behaviors and locomotor activity problems (54).

\section{Potential biomarkers}

Nine genes have met the criteria of biomarker selection in all three samplings. These genes were related to dopamine signaling, transcription factors, and immune system regulations. Also, the deregulation of four genes was getting worse during PME life and had met the criteria in twelve months and twenty-four months' samplings and remained deregulated in thirty-six months' samplings. These genes were related to synaptogenesis, memory formation, and dopamine degradations.

\section{Dopaminergic pathway dysfunction}

Methamphetamine (METH) is an illicit toxic psychostimulant that is widely abused. Its toxic effects depend on the release of excessive levels of dopamine (DA) that activates striatal DA receptors (55). Psychostimulant can produce robust rewarding effects through modulating the dopaminergic synapse, dopamine re-uptake and dopamine- regulated downstream signals. Five genes of the biomarker list are involved in the dopamine pathway, dopamine receptors (D1, D2, D3), brain-derived neurotrophic factor (BDNF) were overexpressed and MAOA down expressed. BDNF is involved in regulating the expression of 
dopamine receptors, especially in methamphetamine abuse and triggers behavioral sensitization, and MAOA are involved in the degradation of dopamine and its downregulation are related to violent behavior $(56,57)$.

The similarity of expression pattern in PME and methamphetamine abuse in adults may support the evidence that methamphetamine can pass through the blood-brain barrier of infants. The up-regulation of dopamine receptors was reduced after twelve months but still significantly high during the next 24 months. About BDNF up-regulation was reduced after 12 months but chronically increased again. These patterns of dopamine pathway over function are well known in several psychiatric disorders such as schizophrenia and bipolar disorder (58). MAOA down-regulation started from first sampling but met criteria of significancy at the twelve months sampling and remains almost constantly during the next 24 months. Findings may suggest that PME children could be at high risk for psychiatric disorders, also may explain the stress and violence problem of PMEs $(4,5,59,60)$.

\section{Immune system dergulation}

Immune system abnormalities in PMEs are the most significant findings of the present study. By the way, the exact genes related to the immune system that meet the criteria of biomarkers are all involved in neurodevelopmental disorders, especially autism spectrum disorder(ASD). (Imbalances in cytokines level such as IL-1B, IL-6, IL-4, IFN- $\gamma$, and TGF-B had reported in ASD. Cytokines are mediators of immunological activity and an increase in infection and toxic exposures. Cytokines participate in normal neural development and function, and abnormal cytokine activity caused by meth neurotoxic effects may lead to several neurological dysfunctions. It may explain some of the similar symptoms of ASDs and PMEs, such as language impairments and lack of communication $(4,5,61)$.

\section{Synaptogenesis abnormalities}

Another shared biomarkers between PMEs and ASDs were SHANK2 and DLG4 genes that are related to synaptogenesis. Lack of function in SHANK2 which is detected in late of follow up (at 24 and 36 months sampling) may cause ASD-like behaviours such as reduced social interaction and social communication and repetitive behaviors $(62,63,64)$.

\section{Transcription factors alterations}

Four transcription factors that are well known in the development of the central nervous system were revealed in the PMEs biomarker list, CREB1, DLG4, MECP2, EGR2, and FOXP2. These genes are essential in memory formation, language function, and cognition. Dysfunction of these genes is involved in several psychiatric disorders such as schizophrenia, bipolar disorder, and depression. Findings may suggest that 
PMEs are vulnerable to affect by psychiatric disorders as well as syndromic and heterogeneous disabilities in executive functions such as memory abnormalities and language impairments $(65,66,67)$.

\section{Hepatotoixicity}

CYP2E1 was the only gene that appeared in the list of biomarkers just in the first time of samplings. CYP2E1 is an essential protein for cytochrome P450 mixed-unction oxidase system that is involved in the metabolism and degradation of drugs, toxic environmental chemicals, and carcinogens along with several basic metabolic reactions such as fatty acid oxidations, ethanol, and glucose metabolism(68). It is reported that inflammatory cytokines such as (IL)-1 beta inhibit the CYP2E1 expression that may cause metabolic abnormalities (69). It seems that abnormal activity of the immune system in PMEs could cause acute but not constant effects on xenobiotic metabolism and several digestive pathways related to glucose and lipids in PME infants. But it may be reregulated during the years.

\section{Conclusion}

Findings may suggest that PMEs are facing several psychological like psychiatric disorders and addiction and somatic problems such as metabolic or immunodeficiency disease during their lifetime. The severity of these problem could be different subject to subject and could be related to time and dosage of exposure. Finding out the nature of these health concern along with early detection of affected pathways may lead to better and targeted preventive health behaviors. Besides mRNA expression patterns, the underlying molecular regulatory networks like DNA methylation alterations, miRNAs and IncRNAs are also important to understand molecular alterations and potential dysfunctions in response to different kinds of METH exposure especially prenatal exposure. It may explain some of complexity that were detected in expression pattern during our follow-up and show the importance of future follow-up studies in different ages, including children at the age of school, after the synaptic pruning period, adolescent and even adulthood. Psychological testings along with molecular evaluations in next years of subjects' life may help to better understanding of PME effects on brain functions.

\section{Material And Methods}

\section{Subject selection}

Participants were recruited from a national cohort project of methamphetamine addiction (NCPM) in Iran, with over twenty thousand methamphetamine-dependent subjects. Infants were referred from female subjects of NCPM to PME group based on voluntary maternal self-report of methamphetamine abuse during pregnancy, confirmed by positive meconium screen, and gas chromatography or mass spectroscopy confirmation. PME infants and mothers were matched to a normal group for maternal race, age of mother and father in pregnancy time, birth-weight category ( $<1500 \mathrm{~g}, 1500-2500 \mathrm{~g},>2500 \mathrm{~g})$, health care insurance situation and education in comparison of infant-mother pairs. Maternal and 
neonatal characteristics were examined for significant differences between the PME group and the normal group (Table 1). No difference was found in the baseline and demographic characteristics between groups.

Mothers were interviewed for sociodemographic and prenatal substance use information. Study assessments and sampling were conducted five times when infants were 1, 12, 24, 30, and 36 months of age. Mothers with less than twenty years of age, with any records of opiates or opioid, derived medication, lysergic acid diethylamide, phencyclidine, cocaine abuse during the pregnancy, any records of severe emotional disorders, low cognitive functioning, or current or history of psychosis and major depressive disorder or usage of antipsychotic drugs were excluded from the study. Children (in infant period) with exclusion criteria including critical illness, multiple gestations, life-threatening congenital anomaly, chromosomal abnormality associated with mental or neurological deficiency, overt clinical evidence of intrauterine infection, or a sibling previously enrolled in the study. The occurrence of any severe somatic or psychological disease or changes in lifestyle such as immigration, adaptation, or parents' divorce during the thirty-six months of follow-up were lead to the exclusion of subjects from the study. Maternal use of alcohol and tobacco and smoking during pregnancy was considered as background variables in both PME and normal comparison groups. Heavy methamphetamine exposure was defined as maternal use at least three days per week across pregnancy. The pattern of use, according to trimester and were showed in Table 2 . Indicated overall decline and quitting methamphetamine use throughout the pregnancy. The level of exposure to other drugs of abuse was calculated as cigarettes per day, ounces of absolute alcohol per day.

At the beginning of the study, 3560 PME infants, including 2217 boys and 1343 girls and 4120 normal infants, including 2252 boys and 1868 girls, were recruited. At the end of the 36 months follow up in the PME group, only 2658 children, including 1287 boys and 930 girls and in normal children group, 3573 children including 2064 boys, and 1509 girls remained in the project and were participated in all terms of sampling and testing. Only these 2658 children in the PME group and 3573 normal children were analyzed for the study, and other children were excluded from the project. Written consent form filled by all mothers after explaining the aim of study for each subject in private. The study approved by the local ethical committee based on Helsinki declaration obligations.

\section{Blood sampling and Microarray Analysis}

Blood samples ( 5 ml, PAXgene vacutainer blood RNA-tubes; PreAnalytiX, Hombrechtikon, Switzerland) were collected between 10.00 and 11.00 AM. Total RNA was extracted from peripheral blood samples immediately after sampling by column Purification kit (GeneJET ${ }^{\text {TM }}$ RNA Purification Kit\#K0732, Thermo scientific, Latvia). RNA quality and integrity examined by Agilent 2100 Bioanalyzer (Agilent Technologies) before the beginning of the microarray process. Gene expression profiling analyses were conducted by using the Affymetrix GeneChip Human Genome U133 plus 2.0 Array Platform containing probes representing 39,000 genes. Preparation of labeled and fragmented aRNA targets, hybridization, and 
scanning was carried out according to the manufacturer's protocol (Affymetrix Santa Clara, CA). A hundred nanograms of total RNA for each sample was processed using the GeneChip 3' IVT Express Kit. RNA was reverse transcribed and converted to double-stranded cDNA prior to biotin labeling during in vitro transcription. Then fifty micrograms of labeled aRNA were fragmented, and quality control (QC) was carried out using the Agilent Bioanalyzer. Fragmented aRNA was hybridized on GeneChip Human Genome U133 Plus 2.0 arrays for sixteen hours at $45^{\circ} \mathrm{C}$. Finally, arrays were washed and stained by using the GeneChip Hybridization, Wash, and Stain Kit on the GeneChip Fluidics Station 450. Then chips were scanned using the Affymetrix GeneChip Scanner 3000, and all arrays passed the QC criteria examination.

The GeneChip analysis was performed in Genesis 2.0 (Gene Logic Inc.) and with Microarray Analysis Suite (MAS) 5.0, Data Mining Tool 2.0, and Microarray Database software (available at http://www.affymetrix.com). All of the genes represented on the GeneChip were globally normalized and scaled to a signal intensity of a hundred. Genes that passed MAS 5.0 criteria for false-positive results reduce included to further assessment. Expression data were analyzed using Genesis 2.0 (GeneLogic Inc., Gaithersburg, MD, USA) and DAVID software (Strand Genomics, Redwood City, CA, USA). Gene expression values were floored to 1, and then log2 transformed. Analysis of variance test (ANOVA) was performed for each gene to identify significant gene expression alteration. Genes with statistical significance were subjected to a post hoc t-test for evaluation of contrasts groups one by one for identification of differences between groups. Two criteria were used in all subjects to determine whether a gene was differentially expressed; Fold change greater than 2 and a $P$ value less than 0.05 . Then $P$ values adjusted for multiple testing correction.

\section{Pathways and gene ontology analysis}

Functional enrichment was conducted on differentially expressed data used for all comparisons. For functional annotation, gene ontology analysis was performed for differentially expressed genes with enrichment algorithms integrated into the online Database for Annotation, Visualization, and Integrated Discovery (DAVID 6.8) $(14,15)$. Kyoto encyclopedia of genes and genomic (KEGG) pathway enrichment tool used for the differentially expressed genes (DEGs) and calculated the enrichment factor (EF) for each term or pathway. The $\mathrm{P}$ values were calculated via hypergeometric tests and go with a correction. Only those $\mathrm{GO}$ terms or KEGG pathways with enrichment of corrected $\mathrm{P}<0.05$ and $\mathrm{EF}>2.0$ were included.

\section{Biomarker assessment}

Detection of most reliable and potential predictor biomarkers and footprint of prenatal methamphetamine exposure effects that could be potentially used for clinical and prognostic aspects are highly desired. Microarray data had analyzed by using Bioconductor and GeneFilter package from R programming language for the removal of low-intensity features. The GeneFilter package was used to filter and select genes from the microarray dataset according to a variety of different filtering mechanisms. Also, the knearest neighbor (KNN) classification was performed using leave-one-out cross-validation. The function 
returns the predicted classifications as its returned value. To the exclusion of any false positive and false negative results DEGs that were meet criteria (Fold change $>2$, multiple comparisons corrected P-value $<$ 0.05 and intensity threshold $>2000$ ) were selected for confirmation with GPCR and classification conducted based on previous studies (16).

\section{Confirmation by quantitative Real-Time PCR}

For confirmation of array data's reliability, mRNA levels of significantly altered genes (fold change $>2$ and $\mathrm{p}<0.05$ ) were quantified by quantitative RT-PCR in all subjects. Blood sampling, RNA extraction, and cDNA synthesis repeated with the same method used for DNA microarray. Primers for all selected genes designed by "oligo7" software and blasted on the NCBI website to check the specificity. Quantitative PCR was performed by using SYBR green (Thermo Scientific Maxima SYBR Green/ROX qPCR Master Mix (2X) \#K0221, Fermentas, Latvia). Triplicate method performed for Quantitative Real-time PCR by using the 7900HT Fast Real-Time PCR System (Applied Biosystems, Foster City, CA, USA). GAPDH used for normalization as an endogenous reference gene.

\section{Statistical analysis}

Statistical analysis analyzed by SPSS, version 26. Descriptive data are expressed as mean \pm SD (range), and the level of statistical significance was set at $P<0.01$. Compliance with normal distribution for continuous variables was assessed via the Kolmogorov-Smirnov test. One way ANOVA analysis was used for statistical differences in multiple group comparisons. Pearson correlation test was used for the evaluation of relations between gene expression data and clinical results. Pearson correlation analysis was conducted to determine the relationship between variables. Bonferroni correction was used for multiple comparisons corrections. Body mass index (BMI), RNA quality and concentration, cDNA synthesis quality, plates/runs of qPCR, and primer efficiency were added as covariates, and persistence of the significant difference in the main effect between groups was assessed by ANCOVA to control any potential confusion.

\section{Abbreviations}

PME: Parental methamphetamine exposure.

MA: Methamphetamine.

CNS: Central nervous system.

BBB: Blood brain barrier.

TJ: Tight junction. 
DTI: Diffusion tensor imaging.

FA: Fractional anisotropy.

HIV: Human immunodeficiency virus.

PIDs: Primary immunodeficiency diseases.

PD: Parkinson's disease.

ADHD: Attention deficit hyperactivity disorder.

METH: Methamphetamine.

DA: Dopamine.

BDNF: Brain derived neurotrophic factor.

ASD: Autism spectrum disorder.

NCPM: National cohort project of methamphetamine addiction.

QC: Quality control.

MAS: Microarray analysis suite.

KEGG: Kyoto encyclopedia of genes and genomic.

DEGs: Differentially expressed genes.

EF: Enrichment factor.

KNN: k-nearest neighbor.

BMI: Body mass index.

\section{Declarations}

\section{Availability of data and materials}

All data are fully available without restriction in Arvin Gene Company data base.

\section{Acknowledgements:}

Present study was funded by Arvin Gene Company. We would like to thanks from all participants of study and their families and health care staffs. 


\section{Funding}

The study were funded by neuroimaging genetic laboratory of Arvin Gene Copmany.

\section{Contributions}

Arvin Haghighatfard is the head of the research team and he participated in study design, laboratory procedure, data analysis and manuscript writting. Soha Seifollahi and Pegah Rajabi, participated in laboratory procedure and data analysis and prepration of parts of manuscript. Niloofar Rahmani and Rojin Ghannad zadeh participated in laboratory procedure.

\section{Corresponding author}

Correspondence to Arvin Haghighatfard.

\section{Ethics declarations}

All process of study performed based on Helsinki declaration obligations. Written consent form filled by all mothers after explaining the aim of study for each subject in private. The study approved by the central ethical committee of Islamic Azad university under number of IR-IAU-3466012.

\section{Consent for publications}

All authors are informed and consent about the submission of manuscript and order of authors.

\section{Competing interests}

The authors declare that they have no competing interests.

\section{References}

1. Ma J, Li XD, Wang TY, Li SX, Meng SQ, Blow FC, llgen M, Degenhardt L, Lappin J, Wu P, Shi J. Relationship between the duration of methamphetamine use and psychotic symptoms: A two-year prospective cohort study. Drug and alcohol dependence. 2018 Jun 1;187:363-9.

2. Office of National Drug Control Policy. Methamphetamine trends in the United States, 2010, Fact Sheet. Available at: . Accessed May 1, 2010.

3. Substance Abuse and Mental Health Services Administration. Treatment Episode Data Set (TEDS). 1999-2009. National Admissions to Substance Abuse Treatment Services, DASIS Series: S-56, HHS 
Publication No. (SMA) 11- 4646. Rockville, MD: Substance Abuse and Mental Health Services Administration; 2011.

4. LaGasse LL, Derauf C, Smith LM, Newman E, Shah R, Neal C, Arria A, Huestis MA, DellaGrotta S, Lin H, Dansereau LM. Prenatal methamphetamine exposure and childhood behavior problems at 3 and 5 years of age. Pediatrics. 2012 Apr 1;129(4):681-8.

5. Smith LM, Diaz S, LaGasse LL, Wouldes T, Derauf C, Newman E, et al. Developmental and behavioral consequences of prenatal methamphetamine exposure: A review of the Infant Development, Environment, and Lifestyle (IDEAL) study. Neurotoxicol Teratol. 2015;51:35-44.

6. Derauf C, Lagasse LL, Smith LM, Newman E, Shah R, Neal CR, et al. Prenatal methamphetamine exposure and inhibitory control among young school-age children. JPediatr. 2012;161:452-9.

7. Callaghan RC, Cunningham JK, Allebeck P, Arenovich T, Sajeev G, Remington G, Boileau I, Kish SJ. Methamphetamine use and schizophrenia: a population-based cohort study in California. American Journal of Psychiatry. 2012.

8. Xue Y, He JT, Zhang KK, Chen LJ, Wang Q, Xie XL. Methamphetamine reduces expressions of tight junction proteins, rearranges F-actin cytoskeleton and increases the blood brain barrier permeability via the RhoA/ROCK-dependent pathway. Biochemical and biophysical research communications. 2019 Feb 5;509(2):395-401.

9. Gonzalez B, Jayanthi S, Gomez N, Torres OV, Sosa MH, Bernardi A, Urbano FJ, Garcia-Rill E, Cadet JL, Bisagno V. Repeated methamphetamine and modafinil induce differential cognitive effects and specific histone acetylation and DNA methylation profiles in the mouse medial prefrontal cortex. Progress in Neuro-Psychopharmacology and Biological Psychiatry. 2018 Mar 2;82:1-1.

10. Warton FL, Taylor PA, Warton CM, Molteno CD, Wintermark P, Lindinger NM, Zöllei L, van der Kouwe A, Jacobson JL, Jacobson SW, Meintjes EM. Prenatal methamphetamine exposure is associated with corticostriatal white matter changes in neonates. Metabolic brain disease. 2018 Apr 1;33(2):507 22.

11. Vuletic D, Dupont P, Robertson F, Warwick J, Zeevaart JR, Stein DJ. Methamphetamine dependence with and without psychotic symptoms: A multi-modal brain imaging study. Neurolmage: Clinical. 2018 Jan;1:20:1157-62.

12. Brinker MJ, Cohen JG, Sharrette JA, Hall TA. Neurocognitive and neurodevelopmental impact of prenatal methamphetamine exposure: A comparison study of prenatally exposed children with nonexposed ADHD peers. Applied Neuropsychology: Child. 2019 Apr 3;8(2):132-9.

13. Roos A, Fouche JP, du Toit S, du Plessis S, Stein DJ, Donald KA. Structural brain network development in children following prenatal methamphetamine exposure. Journal of Comparative Neurology. 2020 Jul;15(11):1856-63. 528(.

14. Kauffmann A, Gentleman R, Huber W. arrayQualityMetrics-a bioconductor package for quality assessment of microarray data. Bioinformatics. 2009 Feb 1;25(3):415-6.

15. Huang DW, Sherman BT, Lempicki RA. Systematic and integrative analysis of large gene lists using DAVID bioinformatics resources. Nature protocols. 2009;4:44-57. 
16. Huang DW, Sherman BT, Lempicki RA. Bioinformatics enrichment tools: paths toward the comprehensive functional analysis of large gene lists. Nucleic acids research. 2009;37:1-13.

17. Plessinger MA. Prenatal exposure to amphetamines: risks and adverse outcomes in pregnancy. Obstet Gynecol Clin N Am. 1998 Mar;25(1)(1):119-38.

18. Zhu L, Zhu J, Liu Y, Chen Y, Li Y, Chen S, Li T, Dang Y, Chen T. Chronic methamphetamine regulates the expression of MicroRNAs and putative target genes in the nucleus accumbens of mice. $J$ Neurosci Res. 2015 Oct;93(10):1600-10.

19. Zhu L, Zhu J, Liu Y, Chen Y, Li Y, Huang L, Chen S, Li T, Dang Y, Chen T. Methamphetamine induces alterations in the long non-coding RNAs expression profile in the nucleus accumbens of the mouse. BMC Neurosci. 2015 Dec;16(1):18.

20. Itzhak Y, Ergui I, Young JI. Long-term parental methamphetamine exposure of mice influences behavior and hippocampal DNA methylation of the offspring. Molecular psychiatry. 2015 Feb;20(2):232-9.

21. Roos A, Stein DJ, Donald KA. Assessing cognition in children with prenatal methamphetamine exposure in South Africa. Comprehensive psychiatry. 2019 Jul.

22. Kwiatkowski MA, Donald KA, Stein DJ, Ipser J, Thomas KG, Roos A. Cognitive outcomes in prenatal methamphetamine exposed children aged six to seven years. Comprehensive psychiatry. 2018 Jan 1;80:24-33.

23. Zhu L, Li J, Dong N, Guan F, Liu Y, Ma D, Goh EL, Chen T. mRNA changes in nucleus accumbens related to methamphetamine addiction in mice. Scientific reports. 2016 Nov;21:6:36993.

24. Feier $\mathrm{G}$, et al. Behavioral changes and brain energy metabolism dysfunction in rats treated with methamphetamine or dextroamphetamine. Neurosci Lett. 2012;530:75-9.

25. Bu Q, et al. NMR-based metabonomic in hippocampus, nucleus accumbens and prefrontal cortex of methamphetamine-sensitized rats. Neurotoxicology. 2013;36:17-23.

26. Clay HB, Sillivan S, Konradi C. Mitochondrial dysfunction and pathology in bipolar disorder and schizophrenia. Int J DevNeurosci. 2011;29:311-24.

27. Rezin GT, Amboni G, Zugno Al, Quevedo J, Streck EL. Mitochondrial Dysfunction and Psychiatric Disorders. NeurochemRes. 2009;34:1021-9.

28. Haghighatfard A, Andalib S, Amini Faskhodi M, Sadeghi S, Ghaderi AH, Moradkhani S, Rostampour J, Tabrizi Z, Mahmoodi A, Karimi T, Ghadimi Z. Gene expression study of mitochondrial complex I in schizophrenia and paranoid personality disorder. The World Journal of Biological Psychiatry. 2018 Nov 15;19(sup3):S133-46.).

29. Ungless MA, Argilli E, Bonci A. Effects of stress and aversion on dopamine neurons: implications for addiction. Neuroscience \& Biobehavioral Reviews. 2010 Nov 1;35(2):151-6.).

30. Brenhouse HC, Sonntag KC, Andersen SL. Transient D1 dopamine receptor expression on prefrontal cortex projection neurons: relationship to enhanced motivational salience of drug cues in adolescence. Journal of Neuroscience. 2008 Mar 5;28(10):2375-82.). 
31. González-Burgos I. From synaptic transmission to cognition: an intermediary role for dendritic spines. Brain and cognition. 2012 Oct 1;80(1):177 - 83.).

32. Fischbach GD. NRG1 and synaptic function in the CNS. Neuron. 2007 May 24;54(4):495-7.).

33. Abbasy S, Shahraki F, Haghighatfard A, Qazvini MG, Rafiei ST, Noshadirad E, Farhadi M, alsadat Shiryazdi A, Ghamari R, Tabrizi Z, Mehrfard R. Neuregulin1 types mRNA level changes in autism spectrum disorder, and is associated with deficit in executive functions. EBioMedicine. 2018 Nov 1;37:483-8.

34. Diaz SD, Smith LM, LaGasse LL, Derauf C, Newman E, Shah R, Arria A, Huestis MA, Della Grotta S, Dansereau LM, Neal C. Effects of prenatal methamphetamine exposure on behavioral and cognitive findings at 7.5 years of age. The Journal of pediatrics. 2014 Jun 1;164(6):1333-8.

35. Luo YL, Bian JW, Zheng ZJ, Zhao L, Han S, Sun XH, Li JF, Ni GX. Effects of methamphetamine abuse on spatial cognitive function. Scientific reports. $2018 \mathrm{Apr} ; 8(1)(3): 1-0$.

36. Warton FL, Meintjes EM, Warton CM, Molteno CD, Lindinger NM, Carter RC, Zöllei L, Wintermark P, Jacobson JL, van der Kouwe A, Jacobson SW. Prenatal methamphetamine exposure is associated with reduced subcortical volumes in neonates. Neurotoxicology and teratology. 2018 Jan 1;65:51 9.

37. Beardsley PM, Hauser KF. Glial modulators as potential treatments of psychostimulant abuse. Adv pharmacol. 2014;69:1-69.

38. Loftis JM, Choi D, Hoffman W, Huckans MS. Methamphetamine causes persistent immune dysregulation: a cross-species. translational report. Neurotox Res. 2011;20:59-68.

39. Krasnova IN, Justinova Z, Cadet JL. Methamphetamine addiction: involvement of CREB and neuroinflammatory signaling pathways. Psychopharmacology. 2016;233:1945-62. doi:10.1007/s00213-016-4235-8.

40. Wires ES, Alvarez D, Dobrowolski C, Wang Y, Morales M, Karn J, Harvey BK. Methamphetamine activates nuclear factor kappa-light-chain-enhancer of activated B cells (NF-KB) and induces human immunodeficiency virus (HIV) transcription in human microglial cells. Journal of neurovirology. 2012 Oct 1;18(5):400 - 10.

41. Cisneros E, Ghorpade I A. HIV-1, methamphetamine and astrocyte glutamate regulation: combined excitotoxic implications for neuro-AIDS. Current HIV research. 2012 Jul 1;10(5):392-406.

42. Langford D, Grigorian A, Hurford R, Adame A, Crews L, Masliah E. The role of mitochondrial alterations in the combined toxic effects of human immunodeficiency virus Tat protein and methamphetamine on calbindin positive-neurons. Journal of neurovirology. 2004 Nov 1;10(6):327 37.

43. Rezaei N, Bonilla FA, Seppänen M, De Vries E, Bousfiha AA, Puck J, Orange J. Introduction on primary immunodeficiency diseases. InPrimary Immunodeficiency Diseases 2017 (pp. 1-81). Springer, Berlin, Heidelberg.

44. Picard C, Gaspar HB, Al-Herz W, Bousfiha A, Casanova JL, Chatila T, Crow YJ, Cunningham-Rundles C, Etzioni A, Franco JL, Holland SM. International union of immunological societies: 2017 primary 
immunodeficiency diseases committee report on inborn errors of immunity. Journal of clinical immunology. 2018 Jan 1;38(1):96-128.

45. Callaghan RC, Cunningham JK, Sajeev G, Kish SJ. Incidence of Parkinson's disease among hospital patients with methamphetamine-use disorders. Movement Disorders. 2010 Oct 30;25(14):2333-9.).

46. Thrash B, Thiruchelvan K, Ahuja M, Suppiramaniam V, Dhanasekaran M. Methamphetamine-induced neurotoxicity: the road to Parkinson's disease. Pharmacological reports. 2009 Nov 1;61(6):966 - 77.

47. Ares-Santos S, Granado N, Espadas I, Martinez-Murillo R, Moratalla R. Methamphetamine causes degeneration of dopamine cell bodies and terminals of the nigrostriatal pathway evidenced by silver staining. Neuropsychopharmacology. 2014 Apr;39(5):1066-80.

48. Azadmarzabadi E, Haghighatfard A, Mohammadi A. Low resilience to stress is associated with candidate gene expression alterations in the dopaminergic signalling pathway. Psychogeriatrics. 2018 May;18(3):190-201.

49. Redza-Dutordoir M, Averill-Bates DA. Activation of apoptosis signalling pathways by reactive oxygen species. Biochimica et Biophysica Acta (BBA)-Molecular Cell Research. 2016 Dec 1;1863(12):297792.

50. Sharikova AV, Quaye E, Park JY, Maloney MC, Desta H, Thiyagarajan R, Seldeen KL, Parikh NU, Sandhu P, Khmaladze A, Troen BR. Methamphetamine induces apoptosis of microglia via the intrinsic mitochondrial-dependent pathway. Journal of Neuroimmune Pharmacology. 2018 Sep 1;13(3):396-411.).

51. Park JH, Seo YH, Jang JH, Jeong CH, Lee S, Park B. Asiatic acid attenuates methamphetamineinduced neuroinflammation and neurotoxicity through blocking of NF-kB/STAT3/ERK and mitochondria-mediated apoptosis pathway. Journal of neuroinflammation. 2017 Dec 1;14(1):240.

52. Chen R, Wang B, Chen L, Cai D, Li B, Chen C, Huang E, Liu C, Lin Z, Xie WB, Wang H. DNA damageinducible transcript 4 (DDIT4) mediates methamphetamine-induced autophagy and apoptosis through mTOR signaling pathway in cardiomyocytes. Toxicology and applied pharmacology. 2016 Mar 15;295:1-1.).

53. Liu HQ, An YW, Hu AZ, Li MH, Wu JL, Liu L, Shi Y, Cui GH, Chen Y. Critical roles of the PI3K-Akt-mTOR signaling pathway in apoptosis and autophagy of astrocytes induced by methamphetamine. Open Chemistry. 2019 Jan 1;17(1):96-104.

54. Winden KD, Ebrahimi-Fakhari D, Sahin M. Abnormal mTOR activation in autism. Annual review of neuroscience. $2018 \mathrm{Jul}$ 8;41:1-23.

55. Guillin O, Diaz J, Carroll P, Griffon N, Schwartz JC, Sokoloff P. BDNF controls dopamine D3 receptor expression and triggers behavioural sensitization. Nature. 2001 May;411(6833):86-9.

56. Narita M, Aoki K, Takagi M, Yajima Y, Suzuki T. Implication of brain-derived neurotrophic factor in the release of dopamine and dopamine-related behaviors induced by methamphetamine. Neuroscience. 2003 Jul 4;119(3):767-75.

57. Guo G, Ou XM, Roettger M, Shih JC. The VNTR 2 repeat in MAOA and delinquent behavior in adolescence and young adulthood: associations and MAOA promoter activity. European Journal of 
Human Genetics. 2008 May;16(5):626-34.).

58. Takahashi M, Shirakawa O, Toyooka K, Kitamura N, Hashimoto T, Maeda K, Koizumi S, Wakabayashi K, Takahashi H, Someya T, Nawa H. Abnormal expression of brain-derived neurotrophic factor and its receptor in the corticolimbic system of schizophrenic patients. Molecular psychiatry. 2000 May;5(3):293-300.

59. Dong E, Dzitoyeva SG, Matrisciano F, Tueting P, Grayson DR, Guidotti A. Brain-derived neurotrophic factor epigenetic modifications associated with schizophrenia-like phenotype induced by prenatal stress in mice. Biol Psychiatry. 2015 Mar;15(6):589-96. 77(.

60. Berton O, McClung CA, DiLeone RJ, Krishnan V, Renthal W, Russo SJ, Graham D, Tsankova NM, Bolanos CA, Rios M, Monteggia LM. Essential role of BDNF in the mesolimbic dopamine pathway in social defeat stress. Science. 2006 Feb;10(5762):864-8. 311(.

61. Goines PE, Ashwood P. Cytokine dysregulation in autism spectrum disorders (ASD): possible role of the environment. Neurotoxicol Teratol. 2013 Mar;1:36:67-81.

62. Won H, Lee HR, Gee HY, Mah W, Kim JI, Lee J, Ha S, Chung C, Jung ES, Cho YS, Park SG. Autistic-like social behaviour in Shank2-mutant mice improved by restoring NMDA receptor function. Nature. 2012 Jun;486(7402):261.

63. Schmeisser MJ, Ey E, Wegener S, Bockmann J, Stempel AV, Kuebler A, Janssen AL, Udvardi PT, Shiban E, Spilker C, Balschun D. Autistic-like behaviours and hyperactivity in mice lacking ProSAP1/Shank2. Nature. 2012 Jun;486(7402):256-60.

64. Berkel S, Marshall CR, Weiss B, Howe J, Roeth R, Moog U, Endris V, Roberts W, Szatmari P, Pinto D, Bonin M. Mutations in the SHANK2 synaptic scaffolding gene in autism spectrum disorder and mental retardation. Nat Genet. 2010 Jun;42(6):489.

65. Enard W, Przeworski M, Fisher SE, Lai CS, Wiebe V, Kitano T, Monaco AP, Pääbo S. Molecular evolution of FOXP2, a gene involved in speech and language. Nature. 2002 Aug;418(6900):869-72.

66. Kandel ER. The molecular biology of memory: CAMP, PKA, CRE, CREB-1, CREB-2, and CPEB. Molecular brain. 2012 Dec;5(1):14.

67. Curie A, Lesca G, Bussy G, Manificat S, Arnaud V, Gonzalez S, Revol O, Calender A, Gérard D, des Portes V. Asperger syndrome and early-onset schizophrenia associated with a novel MECP2 deleterious missense variant. Psychiatric genetics. 2017 Jun 1;27(3):105-9.

68. Rendic S, Carlo FJ. In Human cytochrome P450 enzymes: a status report summarizing their reactions, substrates, inducers, and inhibitors. Drug metabolism reviews. 1997 Jan 1;29(1-2):413580.

69. Hakkola J, Hu Y, Ingelman-Sundberg M. Mechanisms of down-regulation of CYP2E1 expression by inflammatory cytokines in rat hepatoma cells. Journal of Pharmacology and Experimental Therapeutics. 2003 Mar 1;304(3):1048-54.

\section{Tables}


Due to technical limitations, tables are only available as a download in the Supplemental Files section.

\section{Figures}

\section{2 months}

\section{4 months}

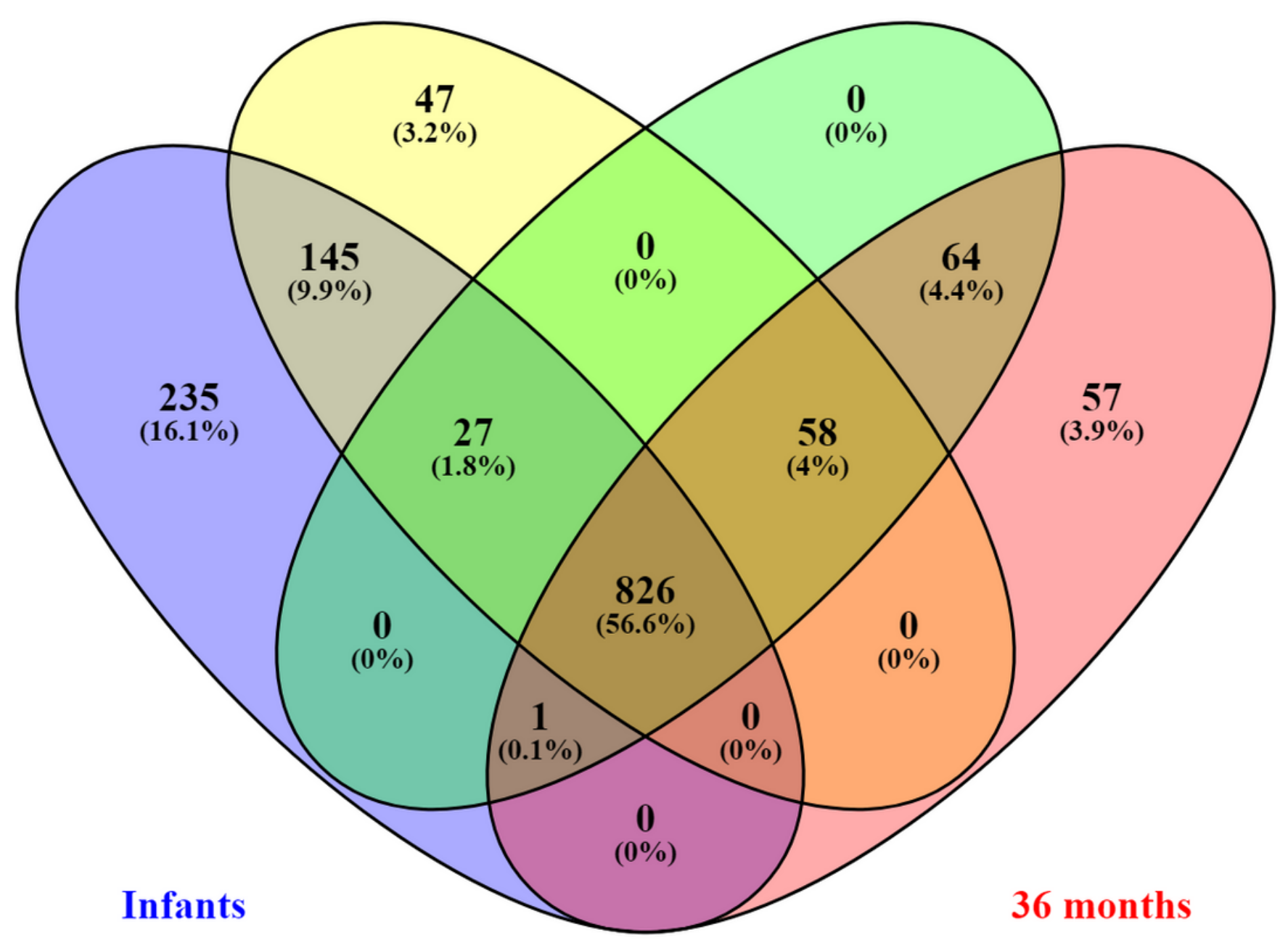

Figure 1

DEGs in response to prenatal meth expouser. Venn diagram showed the common set of DEGs in subjects with prenatal METH exposure during the follow up. None of shared genes showed different directionality 




Figure 2

KEGG pathway analysis. The most significantly related pathway wich were involved during the whole follow up was primary immunodeficiency. Image is from Kyoto encyclopedia of gene and genome. Red genes were differentially expressed in all four samplings in PMEs compared to normal children.

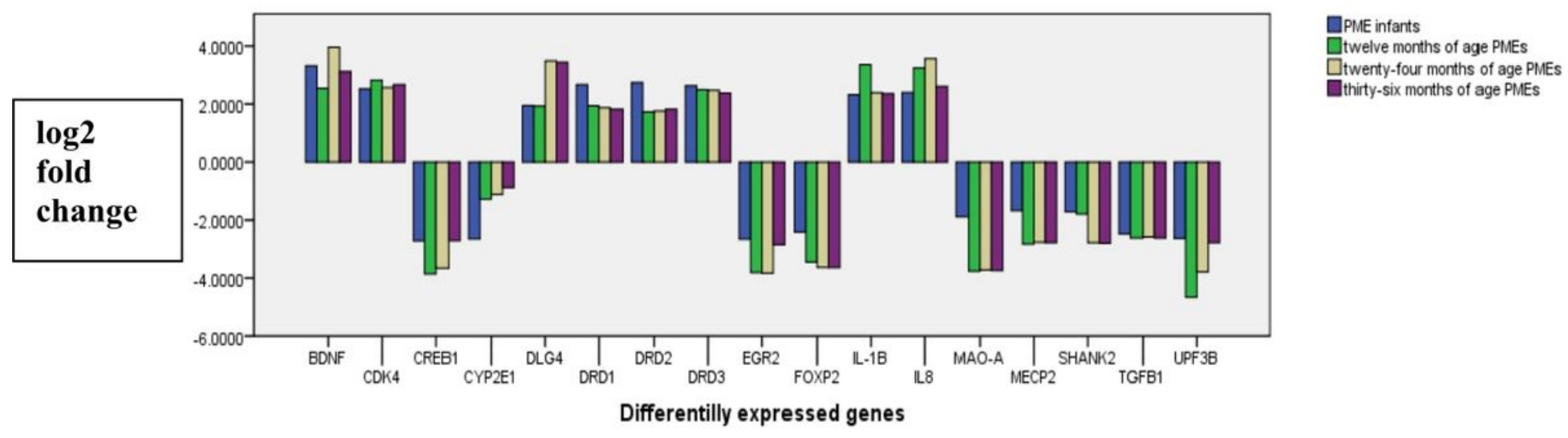

\section{Figure 3}

Potential biomarkers log2 fold change.Significant gene expression changes identified through qPCR in PME children during four time samplings. Expression of normal children presumed as one and revealed as black line. Fold changes of PMEs groups calculated in compare with normal children from matched age group. Blue bars is for infant PMEs, red bars is for twelve months of age PMEs, green bars is for twenty four months of age PMEs and yellow bars is for thirty six months of age PMEs. 


\section{Supplementary Files}

This is a list of supplementary files associated with this preprint. Click to download.

- Tables.docx

- PMEsupplementary1.xlsx

- SupplementarydataPME.docx 